\title{
Famílias e individualismo: tendências contemporâneas no Brasil
}

Lia Zanotta Machado ${ }^{1}$

MACHADO, L. Z. Family and individualism: contemporary tendencies in Brazil. Interface _ Comunic, Saúde, Educ, v.4, n.8, p.11-26, 2001.

This paper presents issues pertaining to the current debate on the present and the future of the "institution of the family", and of the "value" of the family vis à vis the generalization of individualism. In Brazilian society, the code of personal relations transforms relatives and the family into a value that permeates all of society, and that is articulated with the individualist code, leading to a variety of kinds of family organization that abide by the principles of reciprocity and hierarchy, according to class situations and positions. The frail generalization of the conditions of citizenship can transform the principle of individual equality of rights into the universalization of anonymity, of indifference and of desensitization.

KEY WORDS: Family; individualism; reciprocity.

Este artigo apresenta pontos de reflexão sobre o debate atual em torno do presente e do futuro da "instituição família" e do "valor" da família diante da generalização do individualismo. Na sociedade brasileira, o código relacional faz da parentela e da família um valor que atravessa toda a sociedade, e se articula com o código individualista, constituindo variedades de formas de organização familiar que obedecem a princípios de reciprocidade e hierarquia, de acordo com as posições e situações de classe. A fraca generalização das condições cidadãs, pode transformar o princípio da igualdade individual de direitos na universalização do anonimato, da indiferença e da dessensibilização.

PALAVRAS-CHAVE: Família; individualismo; reciprocidade.

${ }^{1}$ Professora do Departamento de Antropologia, Universidade de Brasília, UnB. Coordenadora do Núcleo de Estudos e Pesquisas sobre a Mulher/NEPeM/UnB. <liazan@uol.com.br> 
Este trabalho visa apresentar alguns pontos de reflexão $e$ de discussão sobre o debate atual em torno do presente $e$ do futuro da "instituição família" e do valor da família enquanto categoria classificatória. A cena de fundo do debate é a suposta oposição entre o valor do individualismo e o valor da família. De um lado da arena, estão postos os estudiosos que atribuem a diversidade de formas familiares, a retração ou expansão do valor e do lugar da família numa sociedade, a um paradigma cultural fundante e, do outro, os estudiosos que atribuem as diversidades das formas de família e dos valores atribuídos a uma multiplicidade de causas e de contextualizações, em que uma delas passa pelo modo pelos quais os Estados permitem substituir ou não as funções familiares. Busco aqui afirmar que o grande desafio é aprofundar o debate articulando os argumentos contidos numa e noutra posição. Não se deve deixar que a disposição da arena reifique e simplifique o debate e se parta para uma exaltação do "familismo" ou do "individualismo". Nada há de seguro e inercial na longa duração do valor da família no Brasil, ou de garantia na pretendida crença de que o individualismo das sociedades desenvolvidas reforme em um só sentido linear o futuro das formas e dos valores da família.

As interrogações atuais sobre as tendências contemporâneas das formas de famílias e de parentelas, e das modalidades de se conceber o valor da família na sociedade brasileira, estão inspiradas na grande indagação sobre o futuro da instituição $e$ das parentelas no mundo ocidental diante da expansão do individualismo. O valor conferido ao individualismo no mundo ocidental parece estar pondo em cheque o valor atribuído à família como princípio social balizador. Uma solução lógica e cômoda é a de resolver o impasse, dizendo que se trata agora de aumentar o espaço da "individualização nas organizações familiares". As tensões das formas familiares e suas transformações são muito mais profundas.

Contudo, é certo que, mesmo sem minimizar a diversidade deste chamado mundo ocidental, o crescente processo de individualização consolidou as sociedades de direitos individuais e os "Estados de bemestar". O individualismo, na sua versão da alta modernidade, produziu inequívocos efeitos nas formas familiares, nos seus princípios e nos valores conferidos à esfera familiar.

A situação brasileira, tal como a de toda a América Latina, parece mostrar, em
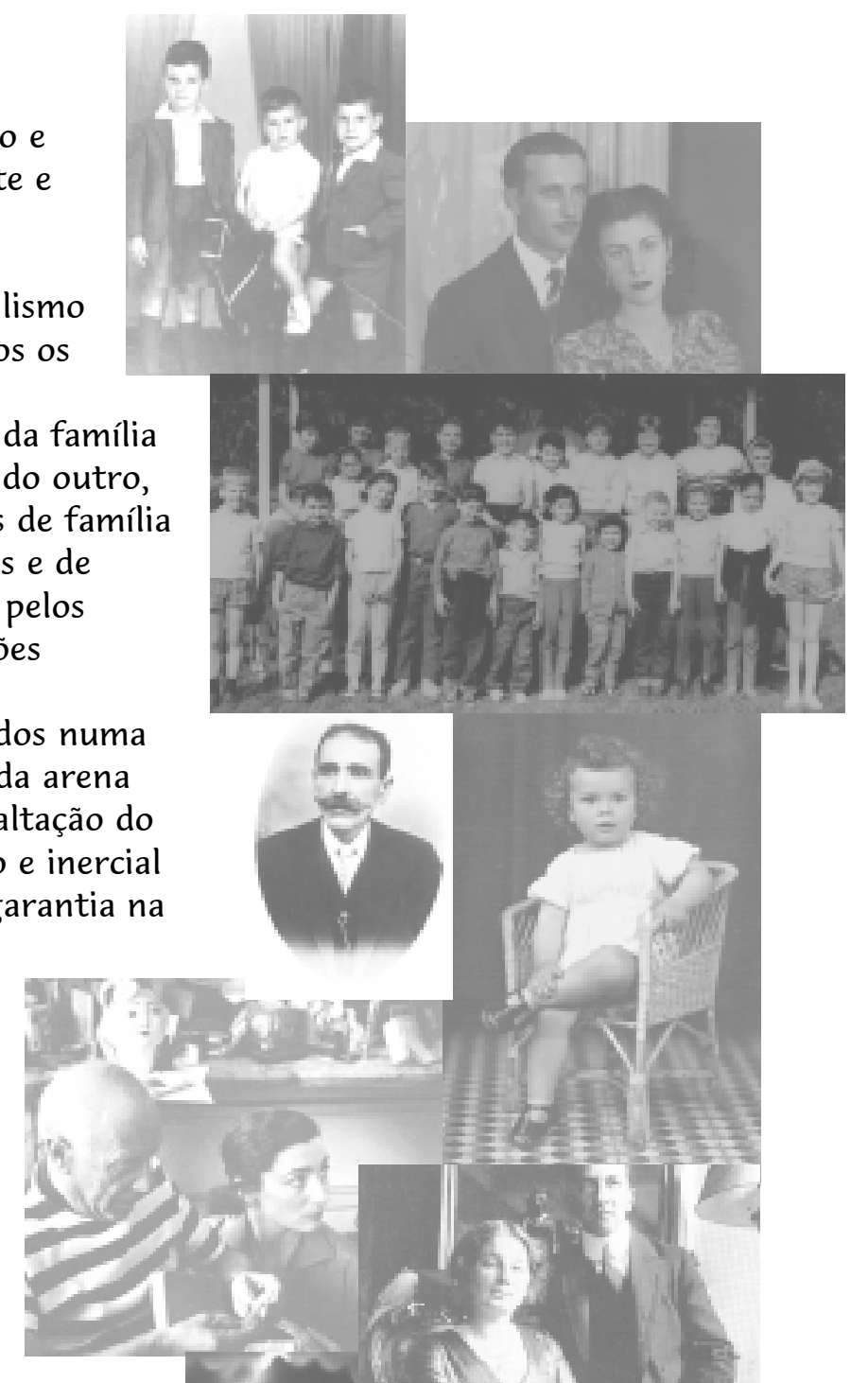
princípio, pelo menos dois pontos diferenciais em relação ao mundo europeu e norte-americano. De um lado, nem no Brasil, nem nas nações hispanoamericanas, se alcançou o Estado de bem-estar ou se generalizaram os direitos cidadãos, tal como, por diferentes percursos, o "mundo ocidental desenvolvido" alcançou. De outro, o paradigma cultural ibero-americano que informa a construção social das formas de família, da sociabilidade e da noção de indivíduo apresenta historicamente forte enraizamento católico, em certo grau arabizado. Muito se distancia também do paradigma cultural luterano-calvinista preeminente no mundo anglo-saxão, mas também presente, em diferentes graus, na Europa Continental, especialmente na não latina. Marca, ainda, sua distância com o paradigma laico, jacobino e iluminista do mundo francês, ainda que tenha sido fortemente permeado pelo romantismo e pela cultura sulina mediterrânea .

François de Singly (2000), sociólogo francês, não duvida das

mudanças que essa instituição (a família) conheceu e conhece ao
longo da segunda metade do século XX - sobretudo nos países
ocidentais: o decréscimo dos casamentos, das famílias numerosas, o
crescimento das concubinagens, dos divórcios, das famílias
pequenas, das famílias monoparentais, recompostas, do trabalho
assalariado das mulheres. (p.13)

Com certeza, ao pensar o mundo ocidental, está pensando o mundo ocidental desenvolvido e não somente o francês, mas nada se pode inferir sobre se está ou não incluindo a América Latina. $O$ autor encontra as orientações teóricas explicativas de tais mudanças no crescimento, desde o início do século $X X$, da centralidade da lógica do grupo familiar em torno do amor e da afeição, grupo estruturado na conjugalidade (com atribuições diferenciais por sexo) e na filiação. A partir dos anos sessenta, as vê, de um lado, no deslocamento da importância do grupo para a importância dos membros do grupo, da crescente idéia de que o amor passa a ser condição da permanência da conjugalidade, e da tendência a não diferenciação de funções por sexo nas relações amorosas e conjugais; de outro, na substituição de uma "educação retificadora" (corretora e moral) das crianças por uma "pedagogia da negociação".

Não estamos longe da interpretação do sociólogo britânico Giddens (1991 e 1992) da novidade do surgimento na "alta modernidade" do "amor confluente" e da "relação pura" em que as diferenças de gênero teriam cada vez menos lugar na conjugalidade, e onde o "amor" também passaria a ser condição para a permanência dos laços conjugais, dissolvendo-se as tradicionais obrigações e diferenciações de funções entre os parceiros amorosos.

Estas duas formas de interpretação sobre os efeitos dos valores do individualismo nos arranjos amorosos e familiares assemelham-se notavelmente. Estão referidas, respectivamente, aos mundos francês $e$ britânico. Subentendem o mesmo substrato de pertencerem ao "mundo ocidental desenvolvido", e não indagam, nenhum, nem outro, sobre a importância metodológica de buscar as "diferenças" nacionais, regionais ou 
de classe. Não é prioritária a atenção sobre os possíveis processos diferenciais ou específicos de constituição de modalidades de famílias que estariam em marcha, subsumidos ou submergidos nas tendências estatísticas gerais aludidas por Singly. Estes resultados estatísticos podem estar respondendo à multiplicidade de paradigmas culturais de âmbitos mais específicos. Os intelectuais dos países centrais do mundo ocidental talvez se vejam, predominante e acriticamente, como um mundo homogêneo "no que importa", relegando-se as diversidades a "preferências ou modalidades nacionais, locais ou de classe", que não são suficientes para colocar em risco as tendências gerais modernas e homogeneizadoras do mundo ocidental. Quando encontram variedades que importam, e que constituem diferenças que se distanciam dos valores modernos dos modelos de família, amor, sociabilidade e indivíduo, relegam tais variedades aos mundos dos outros: "etnias" ou "imigrantes".

Quanto à diversidade de padrões familiares de acordo com a posição $e$ situação de classe, parece que, se elas existem, "não estariam para ficar", mas estariam apenas num momento que precede o passo adiante na direção da reafirmação de um mesmo padrão moderno. Contudo, muitas tensões e modos diversos de vivências e arranjos podem estar sendo encobertos. A título de curiosidade, muito me impressionou a discussão britânica e francesa em programas ${ }^{2}$ de televisão sobre os valores contrastivos da visão positiva da "pedagogia da palmada" (especialmente sustentada por pais e mães de extração social operária e popular) em confronto com a visão negativa (especialmente sustentada por pais e mães de setores médios) que, em nome da "pedagogia da negociação", classifica na mesma categoria disciplinadora $e$ arcaica, a palmada e o espancamento (diferença só de grau).

Os estudos, não poucos, que se fizeram e se fazem nos países centrais europeus sobre as diferentes formas e modalidades locais ou de classe de arranjos familiares, parecem não mais ser capazes de confrontar a atual $e$ reiterada primazia de um geral e moderno modelo familiar, quer francês ou britânico, quer europeu e norte-americano, que, é claro, admitiria variedade de versões, sem que elas se constituam um dilema para indagar sobre a modernidade. No meu entender, está longe o efeito e o lugar simbólico dos estudos históricos britânicos sobre a especificidade das classes operárias. Possivelmente, a expectativa é a de que as diferenças se minimizem ou se dissolvam no ar. E talvez o façam.

No meio intelectual brasileiro, como já demonstraram vários estudiosos, as Ciências Sociais e a História sempre se perguntaram sobre as especificidades brasileiras, "o que faz do Brasil, Brasil”, e sobre as diferenças sociais e culturais no próprio âmbito da sociedade brasileira espelhando, dessa forma, um intento de construir a idéia de nação e uma maneira de construir a idéia de que a nação engloba diversidades. A construção da especificidade jamais se pensou como não se incluindo no "mundo ocidental", entendimento que não é pacífico para intelectuais dos países ocidentais desenvolvidos, que nos vêem, muitas vezes, como exóticos, e certamente como "específicos". Assim, enquanto alguns intelectuais buscavam o padrão ou modelo familiar brasileiro, outros buscavam a diversidade de modalidades e modelos de família no Brasil, por classes e por regiões.
${ }^{2}$ Programas de televisão (de auditório) vistos no decorrer do meu estágio pósdoutoral em Paris, com algumas idas a Londres, durante os anos de 1993 e 1994. 
Historiadores, sociólogos e antropólogos brasileiros já destacaram a importância da "família patriarcal" tal como caracterizada por Gilberto Freyre (1980) em "Casa-grande e Senzala" e em "Sobrados e Mocambos" (1951), para a construção social de um tipo de modelo familiar que fez efeito em toda a sociedade colonial, mas também no período da Independência, da República até a contemporaneidade, senão para impor uma mesma forma de família, mas para instaurá-la como modelo referencial. Enquanto Eni de Mesquita Samara (1983

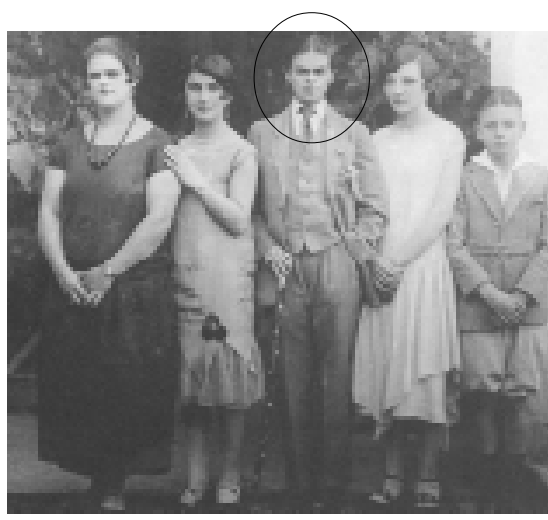

Frida Kahlo e família, 1926 e 1987) e Mariza Correa (1982) enfatizam a diversidade de arranjos e modelos em toda a história colonial e moderna, enfraquecendo a idéia de uma família monolítica gilbertiana de Casa-Grande e Senzala ou de Sobrados e Mocambos, Ângela de Almeida (1987 e 1993) e Roberto da Matta (1985 e 1987) enfatizam a dominância do modelo patriarcal gilbertiano, não só na história colonial como na moderna $e$ contemporânea. Correa e Samara ressaltam como a concubinagem e as famílias monoparentais são presença constante em toda a época colonial, perdurando como "costumes" nas classes populares nos séculos XIX e XX. Samara (1981) lembra-nos que o casamento em São Paulo do século XIX, "era uma opção para apenas uma parcela da população, apesar das argumentações da Igreja e ameaças de punição" (p.32). Trabalhos como o de Bilac (1978) confirmam a importância do tratamento focado na diversidade da situação de classe.

Para Almeida (1987), o modelo patriarcal gilbertiano é referencial, faz parte da formação brasileira e é este modelo que se "casa" posteriormente com o modelo da família nuclear burguesa, "que será reapropriado $e$ adaptado pela mentalidade da família patriarcal” (p.63). Da Matta (1987) entende por modelo patriarcal brasileiro, a

\footnotetext{
parentela de mais de duas gerações, com agregados, que age de modo corporado quando em crise e possui uma chefia indiscutível, bem como recursos de poder que o grupo cuida de manter $e$ distribuir com cuidado e decisão, o que faz também com que esses grupos possam eventualmente chegar ao poder por meio do uso de relações pessoais. (p.119-20)
}

Para ele, este modelo é estruturador de toda uma concepção hierárquica de formas de famílias, completas umas e incompletas outras. A incompletude (famílias monoparentais, famílias sem agregados) das periféricas se deve a sua função de "sustentar" e "servir" às primeiras. Da Matta vai além.

Entende que no Brasil o valor da família como prestígio se estende por toda a sociedade. "Quem não tem família já desperta pena antes de começar o entrecho dramático; e quem renega sua família tem, de saída, a nossa mais franca antipatia" (1987, p.125). O valor da família gira em torno do valor metafórico da "casa" e que chega a constituir um princípio ordenador quase cosmológico: o "mundo da casa" que é percebido como distinto, 
muitas vezes oposto ao "mundo da rua", mundo da universalidade de direitos, mas também da impessoalidade (1985).

A interpretação de que um modelo cultural relacional e hierárquico de sociabilidade se instituiu na sociedade brasileira colonial e permaneceu interrelacionado aos processos posteriores de instituição e construção de um modelo igualitário e individualista em suas diferentes fases está presente em vários autores brasileiros. Especialmente entre antropólogos que, de uma forma ou outra, retomam as indagações teóricas de Dumont (1966 e 1977) na esteira de Mauss (1974). Luiz Fernando Duarte (1986) enfatiza os aspectos "holistas" e "relacionais", pouco ou nada "individualistas" das classes trabalhadoras. Cynthia Sarti (1996) enfatiza a especificidade do paradigma cultural da família como valor moral entre os "pobres e trabalhadores", centrado no princípio da reciprocidade e das obrigações, com preeminência do todo da família e da parentela sobre os indivíduos. Gilberto Velho (1981, 1986 e 1987) enfatiza o valor do individualismo como específico das camadas médias. Se as relações familiares e de parentesco continuam a ser referenciais para as camadas médias, são muito mais dependentes de um fluxo e refluxo e de um acionar destas relações que se percebem como resultado da vontade ou interesse do indivíduo.

Ouvidos o conjunto desses autores, tudo se passa como se a força $e$ o valor dado à parentela estendida enquanto família, e o valor da família como princípio instituidor de uma moral, de prestígio e poder fossem tanto mais preeminentes quanto mais nos aproximamos dos segmentos das classes altas e elites políticas e quanto mais nos aproximamos das classes populares. Para as classes populares, ou "pobres $e$ trabalhadoras", o valor da família é fundamentalmente instituidor de uma moralidade estabelecida por um conjunto de regras de reciprocidade, obrigações e dádiva. Para as classes altas, o valor da família é instituidor de um comportamento "corporado" da parentela estendida em nome do qual se dá um exercício privilegiado de recursos políticos e da transformação de recursos de capital social em capital econômico e político e vice-versa. Caberia às camadas médias serem as depositárias dos valores mais individualistas e mais refratários ao valor da família como valor englobante. Para elas, o valor da família continua a instituir prestígio, relativizada pelo lugar do valor individualista como instituidor primordial de prestígio. Quanto a mim, tenho trabalhado com a co-existência de um código relacional ancorado nas noções de honra, reciprocidade e hierarquia, e de um código individualista. (Machado, 1985; 1997; 1999).

O breve desenho desses modos diferenciados de a família se apresentar, como valor, para as classes altas, médias e populares, tal como absorvo da leitura do conjunto dos autores acima referidos e das pesquisas que venho empreendendo, pode ser um dos fios norteadores para analisar as transformações da contemporaneidade brasileira e mundial e de suas organizações familiares, contextualizando as diferenças de sentido que a expansão do individualismo como valor assume.

A co-existência dos dois códigos, o relacional e o individualista, no meu entender, atravessa, assim, toda a sociedade, constituindo variedades de

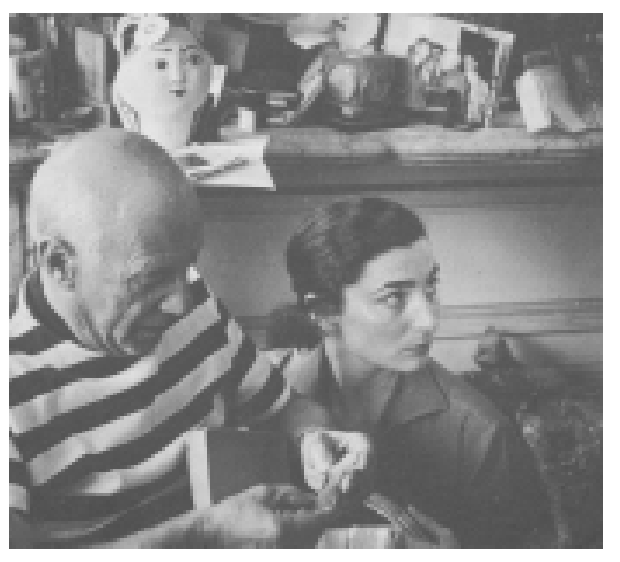

Picasso e a esposa Jacqueline, 1967 


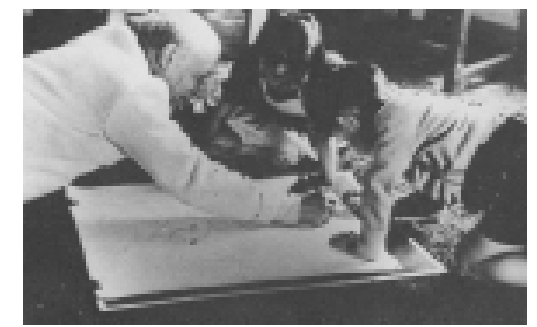

Picasso e os filhos Claude e Paloma formas de articulação e de preeminência de um ou outro código de acordo com as posições e situações de classe. O desafio metodológico é pensá-las nos diferentes segmentos sociais e nas diferentes temporalidades. Outro é também o desafio de não tornar o sentido do individualismo monolítico, diferenciando-se, no mínimo, a presença de uma noção de indivíduo centrada nos direitos de cidadãos de outra centrada nos interesses auto-referidos $e$ no valor da "escolha" e opção auto-direcionada.

Se prezo profundamente o estudo das diferenças e da pluralidade de modalidades de arranjos familiares, estou, por outro lado, totalmente de acordo em afirmar a especificidade brasileira face ao "mundo ocidental central" da importância da presença intensa do "código relacional hierárquico", como uma das matrizes da sociabilidade brasileira, que se condensa no imaginário do "familial" e do "mundo da casa". É a tradução brasileira de sua formação a partir de um paradigma cultural ibérico, arabizado e mediterrâneo, construindo-se numa sociedade colonial e escravocrata, e depois, numa sociedade capitalista periférica que se conservou extremamente desigual e com pouca generalização dos direitos da cidadania igualitária $e$ individual.

No Brasil, tais análises antropológicas fazem eco a historiadores também brasileiros que caminham em torno da história das mentalidades, como Margareth Gonçalves (1987), e de sociólogos e psicanalistas, como Costa (1983) que, geralmente fundamentados em Foucault (1984 e 1985), buscam as distintas "formações discursivas". Sem dúvida, são intelectuais franceses e anglo-saxões predominantes na construção metodológica das Ciências Sociais e da História no Brasil. A diferença que venho apontando aqui, entre as perspectivas dos intelectuais dessas correntes de pensamento, conforme se situem na ótica dos países centrais ou na ótica brasileira, é que no Brasil utilizam-se tais ferramentas para marcar não só as distinções temporais, mas também as espaciais, construindo-se, assim, uma pluralidade de modelos que operam num mesmo tempo histórico. A contemporaneidade brasileira dos arranjos familiares e do valor da família é, assim, também pensada e suposta como plural. Enquanto isso, prioritariamente, nos países centrais, os intelectuais dessas mesmas correntes, seus fundadores, enfatizam as marcas distintivas temporais.

Referindo-se ao século XX na França, Singly (2000) nomeia duas modalidades de famílias modernas.

A 'família moderna I', do período que vai do início do século XX até os anos sessenta - caracterizou-se sobretudo pela construção de uma lógica de grupo, centrada no amor e na afeição." (...) “A 'família moderna 2' se distingue da precedente pelo peso maior dado ao processo de individualização. A família se transforma em um espaço privado a serviço dos indivíduos. Isso é perceptível através de numerosos indicadores do nível da relação conjugal, com a maior independência das mulheres, a possibilidade do divórcio por consentimento mútuo (na França, em 1975), a lei de 1970 que dá fim à autoridade parental, e no nível da relação pedagógica, com o desenvolvimento da negociação das necessidades da criança, de 
novas formas de pedagogia pelas quais a natureza da criança deve ser respeitada mais do que modificada (no período precedente, a educação moral deveria retificar a natureza imperfeita da criança). (p.15)

Com certeza, Singly (2000) é devedor da clássica análise de Philipe Ariès (1981), que situa no século XIX a novidade da instauração de uma família que se quer nuclear e que institui os novos sentimentos da maternidade e da criança, rompendo simbolicamente com a idéia de senso comum da imemorialidade de uma permanente família patriarcal extensa, em que não só a autoridade masculina era imemorial, como o eram os sentimentos de maternidade e afeição em relação à criança. A “família moderna 1", referida por Singly (2000) parece ser a continuidade da família do século XIX de Ariès (1981). Singly (2000) aponta que a "família moderna 2" guarda da precedente a mesma lógica do amor que agora se impõe com mais intensidade. Deixa de apontar, no entanto, a força das tensões entre as diferentes lógicas presentes na primeira e pensadas como excluídas da segunda: a tensão entre a lógica do grupo e a do indivíduo; a tensão entre a divisão hieráquica de gêneros e a divisão igualitária no âmbito da conjugalidade, $e$ ainda a tensão entre a idéia de uma educação moral retificadora da criança $e$ a da pedagogia da negociação. Tais tensões podem estar organizando distintas formas de arranjos. A idéia de tensões é substituída pela idéia da passagem de uma lógica a outra centrada na escolha e na conscientização de "Sophie", personagem de romance que ilustra o nascimento do "eu individualizado". O "eu antigo", o "eu dócil" se transformam em um "eu só" e um "eu com".

Com certeza estas tensões estão presentes no mundo ocidental desenvolvido, constituindo possivelmente diferenças no interior das tendências de formas familiares e dos valores dados à família. No Brasil, as diferenças seriam a "nata" das análises. Na França, o forte da análise é marcar a distinção temporal da "última forma da modernidade da família".

Duas linhagens nos estudos de família são dominantes: uma enfatiza a estrutura e a organização das famílias e outra focaliza a família enquanto valor. Os estudos de família no Brasil também se organizam em torno dessas duas perspectivas. $\mathrm{Na}$ interface das mesmas emerge o grande desafio interpretativo das articulações entre elas. Acredito que este é, atualmente, um dos mais importantes objetivos dos estudos sobre família: a interlocução entre as análises que enfocam a diversidade e as mudanças da estrutura e da organização familiar e as análises que enfatizam o lugar de valor que "a família" $e$ os modelos de família ocupam numa dada sociedade ou segmento social. Esta interlocução supõe e demanda uma maior proximidade e debate entre as análises de cunho mais quantitativo e as análises mais qualitativas.

Esta tendência apresenta à primeira vista vários percalços. As questões suscitáveis pela análise parcial e preliminar de uma única tabela com dados nacionais sobre "família" de 1999, comparados aos de 1995, obtidos pela Pesquisa Nacional por Amostra de Domicílios (PNAD, 1995; 1999), podem servir de estratégia para apontar a diversidade de formas possíveis de construir e configurar as tendências contemporâneas das famílias no Brasil. 
Uma primeira e ingênua leitura poderia facilmente entender os dados da tabela intitulada "Famílias e Pessoas Residentes em Domicílios Particulares, por Condição de Família, segundo algumas Características", como a comprovação de que o Brasil caminha linearmente em direção ao padrão da "família moderna 1 ou moderna clássica". E, talvez já adentrando na direção ao padrão da "família moderna 2 ou da alta modernidade".

Comparando-se 1995 e 1999, o número médio dos residentes em domicílios particulares decresce de 3,6 para 3,4. Este número é tomado como indicador do "tamanho médio da família", já que a coabitação na unidade domiciliar se dá privilegiadamente em torno das relações conjugais, filiais e de parentes afins ou consangüíneos dos chefes: os residentes não parentes, nem filhos, nem cônjuges dos chefes, representam apenas $0,9 \%$ dos residentes em 1995 e 0,3\% em 1999. As famílias com chefias monoparentais, isto é, sem cônjuge residente no domicílio, crescem de $29,33 \%$ para $31,43 \%$.

Tanto em 95 quanto em 99, a maioria das chefias monoparentais é de mulheres. Contudo, de forma contrastiva, aumenta proporcionalmente o número de mulheres chefes que passa a informar a presença de um cônjuge no domicílio. Se em 1995 para cada chefia masculina correspondia a taxa de coabitação conjugal de 0,91 , e para cada chefia feminina a baixíssima taxa de coabitação conjugal de 0,03; em 1999, a taxa de coabitação conjugal em referência à chefia masculina apresenta um leve decréscimo para 0,90 e a taxa em referência à chefia feminina tem acréscimo ligeiramente mais significativo para 0,09 .

Apoiando-se na diminuição do número médio de filhos por chefe presente no domicílio e na relativa continuidade majoritária da coabitação de cônjuges no domicílio, pode-se chegar a afirmar a consolidação da "família moderna 1". Com certeza, a centralidade do valor da divisão hierárquica de gênero no "contrato conjugal" tradicional demanda um provedor para cada novo casal que institui um novo domicílio e assim se dá uma retração da hierarquia intergeracional. Este contrato conjugal tradicional em diferentes vertentes é majoritário entre segmentos de classes populares e médios. Mas, há aqui sentidos distintivos. É pouco verossímel, dados os resultados de várias pesquisas qualitativas, supor nos estratos populares brasileiros a ocorrência da mesma ruptura, presente nos países centrais e nas camadas médias brasileiras, entre o espaço íntimo do domicílio e a rua , e supor ainda o simultâneo esmaecimento da idéia de parentela. O processo de transformar as relações de vizinhança em relações de parentesco e vice-versa (Machado, 1985b; Sarti, 1996) acaba por instituir a noção de "pedaço" (Magnani, 1984), território simbólico de parentes e conhecidos que faz avançar o mundo da família e dos princípios relacionais sobre o mundo da rua e dos princípios vivenciados pelas classes populares como o do anonimato, da indignidade $e$ da indiferença .

Apoiando-se no crescimento das famílias monoparentais, e em outros dados relativos ao grande

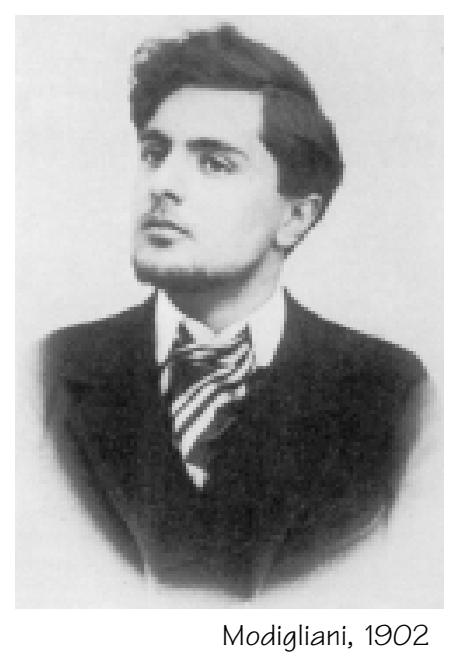

fevereiro, 2001 
número de uniões consensuais no Brasil, poder-se-ia supor, talvez, a presença de características da "família moderna 2", gestada pela idéia do "amor confluente" da alta modernidade. Contudo, este dado aparece logo como inverossímel, pois supõe a presença de uma intensificação e generalização da idéia da autonomia e de um espaço interior e íntimo da individualidade que não parece presente na maior parte das camadas populares que são a maioria da população. Tais valores correspondem mais ao individualismo tal como generalizado nos segmentos médios da sociedade, escolarizados e psicologizados. Contudo, não é possível descartar a presença, nesses grandes números, de uma parcela de famílias monoparentais, ou mesmo biparentais, que constróem seus arranjos amorosos, conjugais e parentais, sob a égide não só do ideal de igualitarismo nas relações de gênero como do ideal de um "amor confluente".

O impacto preliminar da leitura dos dados da leitura do PNAD nos leva, quase "naturalmente", à idéia da família nuclear, ainda que acrescida de alguns parentes, e nos leva, também "naturalmente", longe da idéia de família patriarcal estendida, contendo toda uma parentela extensa no espaço da casa. É claro, no entanto, que não se pode confinar a operacionalidade de uma família-parentela a qualquer

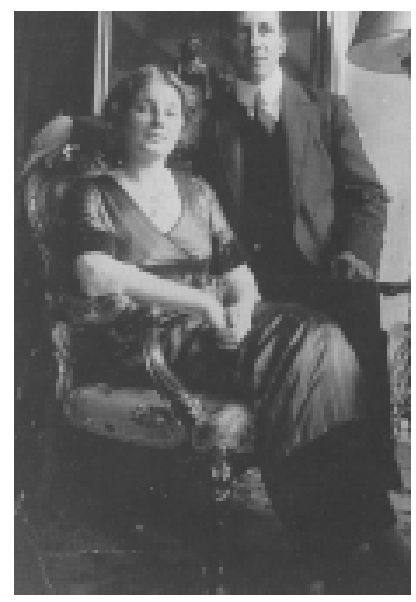

Mondrian e sua noiva, 1914 espaço exclusivo de um domicílio particular. A idéia de família que é visibilizada pela tabela está restrita a este domicílio particular. Por isso, tem um efeito simbólico de, imperceptivelmente, identificar e traduzir a idéia de família como lugar de coabitação predominante de cônjuges e filhos, seguida de parentes e não parentes. De qualquer modo, estes dados permitem dizer que o tamanho médio dos arranjos familiares no Brasil afasta qualquer hipótese da predominância quantitativa de famílias e parentelas estendidas num mesmo espaço domiciliar. De outro lado, não permitem dizer que a parentela estendida deixou de ser uma forma de sociabilidade preeminente $e$ importante em vários segmentos da sociedade brasileira e de que o valor da "família estendida" não seja o modelo familiar que esteja urdindo, ao mesmo tempo, a maior parte das famílias biparentais e monoparentais dos segmentos populares.

Atrás da aparente nuclearização das famílias de classes populares estão tecidas redes de parentela extensa e circulação de crianças como tão bem nos mostram Sarti (1996) e Fonseca (1987 e 1995). Tanto mulheres que sustentam seus filhos, sozinhas, trazem parentes para sua casa, para ajudarem a cuidar dos filhos, quanto outras deixam seus filhos aos cuidados de parentes, especialmente suas mães. Sempre em nome das regras de reciprocidade: dar, receber e retribuir entre a parentela. A percepção de um todo relacional precede os movimentos individuais que nada mais fazem que atualizá-lo. Estes princípios de reciprocidade se fazem em torno de um território simbólico e constituem um valor moral, nos termos de Sarti.

É a identificação do modelo de "família- parentela-estendida", que comporta relações de obrigação e reciprocidade entre consangüíneos e afins, que permite conferir sentido a muitos dos arranjos monoparentais familiares, não se opondo logicamente um a outro. Contudo, nem todos os espaços onde se instauram as classes populares apresentam o mesmo grau 
${ }^{3}$ Os dados das entrevistas que sustentam a forma de "relato livre" que farei a seguir, foram obtidos junto a sujeitos envolvidos em situação de violência, "clientes" da Delegacia Especializada da Mulher (DEAM/D.F.) a partir de 1995, diretamente nas comunidades periféricas e junto aos "clientes" de um hospital regional no D.F., a partir de 1998. A pesquisa é coordenada pelo Núcleo de Estudose Pesquisas sobre a Mulher/NEPeM e conta com a participação de pesquisadores estudantes.

${ }^{4}$ A "honra" é um conceito relacional $e$ coletivo, atribuído a uma totalidade que circunscreve "pessoas" frente a outras totalidades. A honra atribuída a uma pessoa está na estrita dependência da atuação desta pessoa no eixo de regras hierárquicas (de gênero $e$ idade) de direitos e deveres e de obediência a moralidades. Quanto ao código

individualista, está assentado nas idéias de igualdade, liberdade e cidadania, embora tenda a se desenvolver o individualismo das "singularidades". Ver Machado (1985; 1997). de organização e enraizamento da população. Assim, algumas famílias monoparentais e biparentais posicionam-se em espaços onde as parentelas mais amplas são ausentes e onde também é difícil instituir um "pedaço".

O modo como percebo as transformações da contemporaneidade no que tange às formas familiares e aos valores que envolvem e constituem a idéia de família e seus arranjos se entrelaçam com o modo de como indago sobre as transformações contemporâneas das relações de gênero, a partir do mais recente campo de observação privilegiado das minhas pesquisas: a conflitualidade $e$ a violência nas relações amorosas e familiares ${ }^{3}$ que se acrescentaram a estudos anteriores em que a indagação incidia sobre as relações de gênero nos arranjos familiares de segmentos populares e sua inserção urbana (Machado, 1985a; 1985b).

Tenho trabalhado com a simultaneidade da atualização do que venho denominando "códigos relacionais da honra" e "códigos baseados nos valores do individualismo de direitos" ${ }^{\text {, tal como depreendo das narrativas }}$ dos entrevistados e entrevistadas. Esta indagação teórica que sempre imprimi às minhas pesquisas, quer se tratassem de segmentos médios ou populares, derivaram-se de um temor de reificar e enrijecer as distâncias na construção das subjetividades nas classes populares e médias.

Ao ouvir as narrativas de segmentos populares, impressiona-me a simultaneidade da presença dos dois códigos nos sentidos dados tanto pelos sujeitos investigados envolvidos em situação de violência física, quanto pelos que não se referiram a elas. Ainda que as auto- referências se façam predominantes, como se tratasse de uma subjetividade imediatamente colada ao seu lugar estatutário como pessoa num mundo relacional em que o todo precede o indivíduo, a "naturalização da idéia de mulher ou de homem englobada pelo mundo relacional da parentela", grande parte de seus lugares estatutários são postos em interrogação. Enredam-se homens $e$ mulheres entre um código e outro porque os valores inscritos em cada código muitas vezes são referidos como contrários e contraditórios. Participam homens e mulheres de "relações conjugais" que supõem um "contrato conjugal", muitas vezes tradicional, baseado na troca entre a "sexualidade virtuosa da mulher" e "seus afazeres domésticos" (cuidados com os filhos $e$ a casa), de um lado, $e$ a situação de "provedor" do companheiro. Mesmo, sendo cúmplices e pactuantes deste contrato conjugal tradicional, as representações de um e outro se diferenciam.

Concentro-me nos casos de violência conjugal. Eles, em nome da honra, e da função de provedor, podem controlar, fiscalizar e punir suas companheiras. Permitem-se, porque homens provedores, cercear o direito de ir e vir, de impedir o acesso ao trabalho de suas companheiras, de inspecionar órgãos sexuais para garantir que não houve traição, $e$ "bater" se sentem ciúmes ou se não recebem a atenção requerida. Contudo, ainda que saibam e se refiram à ilegitimidade da violência, em função dos direitos da companheira, prevalece a legitimidade do valor da "honra" e a legitimidade do poder derivado de sua função de provedor, em nome do qual consideram legítimo seu comportamento, minimizando e marginalizando o (re)conhecimento dos direitos individuais das companheiras.

Para elas, o contrato conjugal tradicional, ainda que supondo deveres 
diferenciados, não implica poderes desiguais entre homens e mulheres. Suas narrativas contam as expectativas de um companheiro que, na esfera da sociabilidade entre eles e na divisão de poderes na sociedade conjugal, são referidos e pensados como iguais. O gesto violento, o controle do ir e do vir, o controle do acesso ao trabalho e ao estudo, de forma alguma, são legitimados como direitos naturais. Não cabem aos homens tais poderes, porque homens e mulheres são entendidos como iguais. Os homens violentos parecem estar ainda referidos à ordenação do Código Civil de 1916 em que a mulher dependia da autorização do marido para trabalhar.

Há uma expectativa em intelectuais como Bourdieu (1998) e Giddens (1992) que a revolução simbólica das posições hierárquicas e de poder entre os gêneros se possa fazer pela reinvenção amorosa. Têm razão, se consideram que este âmbito, se mudado, poderia ser o lugar desta revolução simbólica final. Não têm, se imaginam que este seja o âmbito que possa se constituir em passagem facilitadora para tal revolução simbólica. Se me deixo escutar os dizeres das mulheres, conferindo todo o seu sentido sobre seus processos amorosos, é no "amor" que se esconde a mais difícil armadilha. Explicita-se a relação amorosa como relação entre iguais, mas aí mesmo se funda o mais impensado dos fulcros tradicionais das relações hierarquizadas de gênero.

É na esfera das representações amorosas e afetivas que as mulheres entrevistadas parecem valorizar e buscar, sem reconhecer, um companheiro amante porque delas protetor e continente. Assim, sem saber, já colocam seus parceiros numa posição englobadora e hierarquicamente superior. Muitas vezes, buscando um amor marcado pela qualidade de um parceiro protetor, é que se encontra um companheiro possessivo, controlador e violento. É no contrato amoroso marcado pelas posições hierárquicas entre o masculino e o feminino, presente nas expectativas femininas, muitas vezes vividas na ordem do "impensado" que rege o sentimento do amor que se pode entender como se realizam "contratos conjugais" tão pouco negociados entre os parceiros.

Muitas são as narrativas de mulheres que, depois de um "contrato conjugal" fracassado, se interditam de realizar uma nova relação amorosa que implique em coabitação. Acreditam menos na consensualidade das expectativas femininas e masculinas. Sabem (reconhecem) que os homens provedores tendem a chamar a si o direito do controle da mulher e dos filhos. A força dos valores tradicionais da família lhes aparece como inamovível. Obrigam-se a serem cúmplices da idéia de que a posição de provedor institui o direito ao poder sobre os filhos que residam no domicílio. Prevendo a conflitualidade entre os filhos e o companheiro, ou porque há filhos mais velhos que já ajudam na posição de provedor, e que podem deixar de fazê-lo em situação de conflito, ou porque têm filhos menores sobre os quais não querem perder a autoridade, não se permitem, nem permitem que o companheiro more com elas. Com isso, mantêm a autoridade sobre os filhos e sobre si mesmas. Os dados estatísticos do aumento notável na sociedade brasileira de domicílios mono-parentais, em que a chefia da família é feminina, podem ser também indicadores do aumento da circulação de homens e, talvez, de suas dificuldades de se 
posicionarem ou como provedores ou como controladores de suas companheiras.

Esta auto-interdição da coabitação, tão freqüente nas camadas populares, foi omitida pela interpretação exclusiva da mulher sozinha como o lugar da falta, aquela que é rejeitada ou "não consegue companheiro". Embora não acreditando no "amor confluente", por outros caminhos busca relações sexuais e amorosas que não lhe retirem o poder parental ou o poder sobre si mesma. Contraditoriamente comparte a idéia intocável do todo hierarquizado da família, de outro, reinventa a auto-percepção como indivíduo de subjetividade submetida. A partir da reflexão sobre casos como estes, pode-se apontar como, dados os valores fortemente enraizados do modelo familiar da divisão de gênero no contexto do mundo dos "pobres e trabalhadores", as famílias recompostas destes segmentos se diferenciam dos segmentos médios. Se há uma longa tradição de superposição de uma série de mães e de pais, e de mães-avós e pais-avôs quando resultado de uma "dádiva" da mãe ou do pai obedecendo, assim, ao código relacional familiar, há quase uma interdição para a superposição de pais ou mães nas famílias recompostas. O novo marido da mãe só poderá se constituir pai na ausência do pai biológico tanto como pai cuidador quanto como pai provedor.

Em outro contexto, os segmentos sociais médios, homens e mulheres estão alcançando a reinvenção de novos arranjos familiares, com famílias recompostas orientadas por distintos valores. Dadas as expectativas de maior igualdade de direitos e funções entre mulheres e homens na sociedade conjugal e dado o valor atribuído ao espaço da individualização das ações na família, podem se sobrepor pais e padrastos, mães e madrastas. De outro lado, a "dádiva" de filhos está cada vez mais tendendo a ser interditada e a conseqüente idéia assemelhada de superposição de mães-avós e pais-avôs tende a ser vista como concorrencial e, portanto, cada vez mais interditada, nos casos de uma conjugalidade adulta, de tal modo que as relações avósnetos pode estar começando a diminuir sua importância.

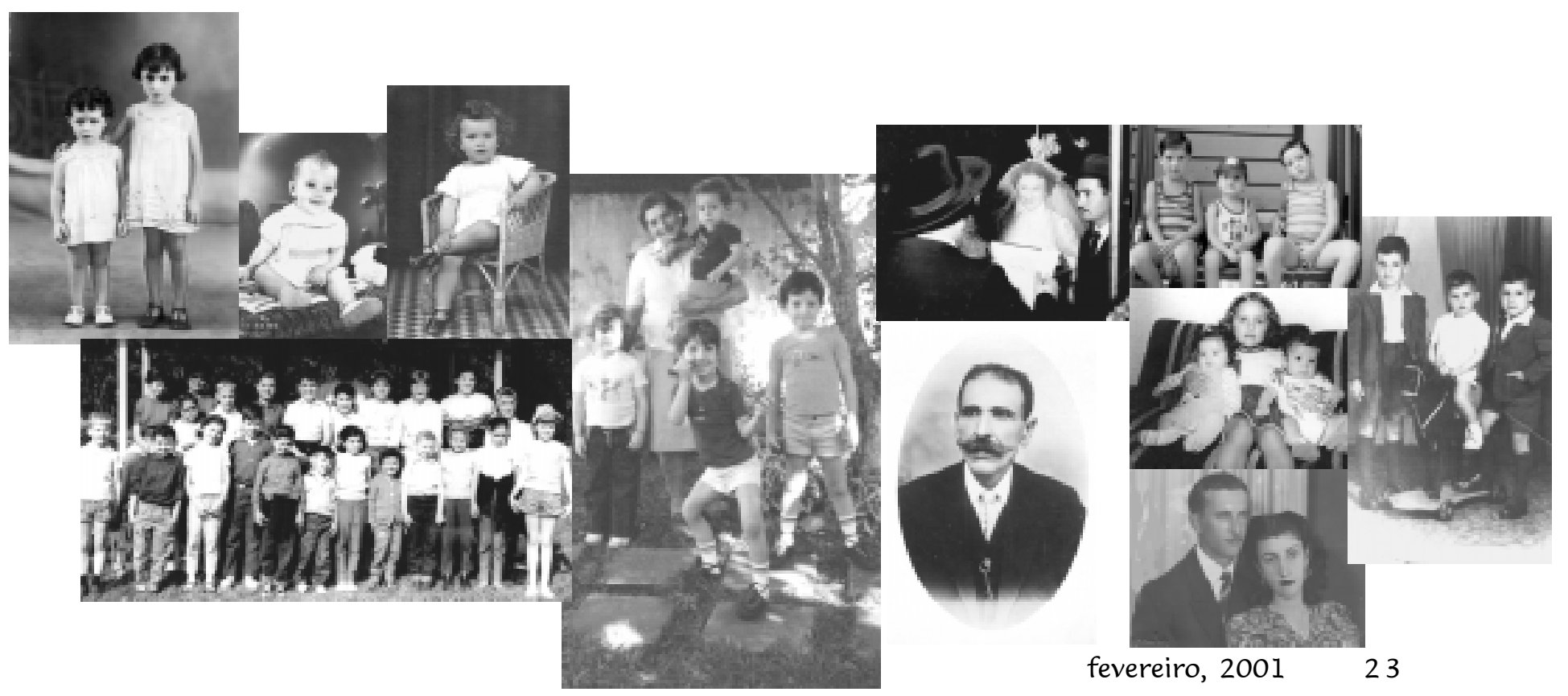


As tendências contemporâneas da família no Brasil, como, de resto, mundialmente, ou no mundo ocidental desenvolvido não podem ser reiteradamente analisadas como se obedecessem a um caminho linear único ou como se este caminho altamente moderno contivesse toda $e$ todas as idéias do "bem". Ao lado mesmo de uma certa tendência homogeneizadora no ocidente presente tanto nos valores individualistas quanto nos efeitos da redução da fertilidade e da natalidade, não se pode perder a riqueza das diferenças presentes e das reinvenções possíveis das diferenças, nem deixar de apostar na possível e revolucionária reinvenção das relações de gênero, no sentido da construção de relações igualitárias.

Por último, uma breve alusão a um tema que merece todo um outro aprofundamento: a pergunta de como as famílias se instituem como "fábricas de construção de subjetividades".

Se o "código relacional da honra", tão presente nos modelos tradicionais das famílias brasileiras, é em grande parte responsável pela legitimação de relações violentas no seu âmbito e pela legitimação das relações hierárquicas $e$ de poder de gênero, este mesmo código é, em grande parte, responsável pela legitimação de relações baseadas na reciprocidade e na responsabilidade do pertencimento a uma comunidade social.

De outro lado, o "código individualista", cada vez mais presente nos modelos das famílias da modernidade clássica e da alta modernidade, é em grande parte responsável pela responsabilização $e$ autonomização dos indivíduos, e pela dessensibilização do indivíduo em relação ao seu semelhante e em relação ao seu pertencimento social, diminuindo a apreensão dos seus limites e da sua situação de compartilhamento.

Um e outro código, enquanto princípios estruturadores das sociedades, tal como pensado por Mauss (1974) e Dumont (1977), não se inscrevem apenas na instituição de modelos familiares. Um e outro estão presentes $e$ informam também a mesma esfera pública e permeiam as diferentes configurações dos Estados nacionais. Retoma-se, assim, a questão das relações entre Estado e famílias, Estado e cidadãos, questão que merece todo um capítulo à parte, mas também imprescindível para estabelecer uma perspectiva das futuras tendências. Este não era o objetivo primordial deste texto, mas é fundamental deixá-la aqui registrada.

A fraca generalização das condições cidadãs no Brasil, as situações econômicas desfavoráveis ou de crise podem fazer emergir o "pior dos dois mundos": não o princípio da reciprocidade hierárquica, mas o da exclusiva hierarquia desigual; não o princípio da igualdade individual de direitos $e$ deveres mas o da universalidade do anonimato, da indiferença e da dessensibilização. A utopia seria construir um mundo cultural que valorizasse o mundo das relações personalizadas e afetivas fortes com o mundo dos direitos iguais. 
ALMEIDA, A. Notas sobre a família no Brasil. In: ALMEIDA, A.M. et al. (Orgs.) Pensando a família no Brasil. Rio de Janeiro: Espaço e Tempo/UFRRJ, 1987. p.53-66.

ALMEIDA, A. O gosto do pecado. Rio de Janeiro: Rocco, 1993.

ARIÈS, P. História social da criança e da família. Rio de Janeiro: Zahar, 1981.

BILAC, E. Famílias de trabalhadores: estratégias de sobrevivência. São Paulo: Símbolo, 1978.

BOURDIEU, P. A dominação masculina revisitada. In: LINS, D. (Org.) A dominação masculina revisitada. Campinas: Papirus, 1998. p.11-27.

CORREA, M. Repensando a família patriarcal brasileira. In: CORREA, M. (org.) Colcha de Retalhos. São Paulo: Brasiliense, 1982. p.13-31.

COSTA, J. F. Ordem médica e norma familiar. 2.ed. Rio de Janeiro: Graal, 1983.

DAMATTA, R. A casa e a rua: espaço, cidadania, mulher e morte no Brasil. São Paulo: Brasiliense, 1985.

DA MATTA, R. A família como valor: considerações não-familiares sobre a família à brasileira. In: ALMEIDA, A. M. et al. (Orgs.) Pensando a família no Brasil. Rio de Janeiro: Espaço e Tempo/ UFRRJ, 1987. p.115-36.

DUARTE, L. F. Da vida nervosa nas classes trabalhadoras urbanas. Rio de Janeiro: Jorge Zahar/ CNPq, 1986.

DUMONT, L. Homo Hieraquicus. Paris: Gallimard, 1966.

DUMONT, L. Homo Aequalis. Paris: Gallimard, 1977.

FONSECA, C. Aliados e rivais na família: o conflito entre consangüíneos e afins. Rev. Bras. Ciênc.

Soc. ANPOCS, v.2, n.4, p.88-104, 1987.

FONSECA, C. Caminhos da adoção. São Paulo: Cortez, 1995.

FOUCAULT, M. História da sexualidade 2: o uso dos prazeres. Rio de Janeiro: Graal, 1984

FOUCAULT, M. História da sexualidade 3: o cuidado de si. Rio de Janeiro: Graal, 1985.

FREYRE, G. Casa-grande e senzala. 20.ed. Rio/Brasília: José Olympio/INL, 1980.

FREYRE, G. Sobrados e mocambos. 2.ed. Rio de Janeiro: José Olympio, 1951.

GIDDENS, A. The transformation of intimacy. Cambridge: Polity Press, 1992.

GIDDENS, A. Modernity and self-identity. Cambridge: Polity Press, 1991.

GONÇALVES, M. Expostos, roda e mulheres: a lógica da ambigüidade médico-higienista. In: ALMEIDA, A. M. et al. (Orgs.) Pensando a família no Brasil. Rio de Janeiro: Espaço e Tempo/UFRRJ. 1987. p.37-52.

MACHADO, L. Z. Honra, família e individualismo. Anuário Antropológico, n. 85, p.138-51, 1985.

MACHADO, L. Z. Morrer e matar no feminino e no masculino. In: LIMA, R.; OLIVEIRA, D.;

GERALDES, E. (Orgs.) A primavera já partiu. Petrópolis: Vozes e M.N.D.H., 1997. p.96-121.

MACHADO, L. Z. Sexo, estupro e purificação. In: SUÁREZ, M.; BANDEIRA, L. (Orgs.) Violência, gênero e crime no Distrito Federal. Brasília: Paralelo 15 e Ed. da UnB, 1999. p.297-352.

MACHADO, L. Z. Perspectivas em confronto: relações de gênero ou patriarcado contemporâneo? Série Antropológica, n. 284, Brasília, p.2-19, 2000.

MACHADO, L. Z.; MAGALHÃES, M. T. Violência conjugal: os espelhos e as marcas. In: SUÁREZ, M.; BANDEIRA, L. (Orgs.) Violência, gênero e crime no Distrito Federal. Brasília: Paralelo 15 e Ed. da UnB, 1999. p.173-237.

MACHADO, L. Z.; MAGALHÃES, T. Imagens do espaço, imagens de vida. In: PAVIANI, A. (Org.) Brasília, ideologia e realidade. Espaço urbano em questão. São Paulo: Projeto/CNPq, 1985b. p.191-214.

MAGNANI, J. G. Festa no pedaço: cultura popular e lazer na cidade. São Paulo: Brasiliense, 1984. 
MAUSS, M. Ensaio sobre a dádiva. In: MAUSS, M. Sociologia e Antropologia. 1.ed. São Paulo: EDUSP/EPU, 1974. p.37-184.

PEIXOTO, C. Avós e netos na França e no Brasil: a individualização das transmissões afetivas e materiais. In: PEIXOTO, C. et al. Família e individualização. Rio de Janeiro: FGV, 2000. p.95111.

PNAD. Pesquisa Nacional por Amostra de Domicílios. 1995, IBGE.

PNAD. Pesquisa Nacional por Amostra de Domicílios. 1999, IBGE.

SAMARA, E. M. Casamento e papéis familiares em São Paulo no século XIX. Cad. Pesq., n.37, p.1725, 1981.

SAMARA, E. M. A família brasileira. São Paulo: Brasiliense, 1983.

SAMARA, E. M. Tendências atuais da história da família no Brasil. In: ALMEIDA, A. M. et al. (Orgs.)

Pensando a família no Brasil. Rio de Janeiro: Espaço e Tempo/UFRRJ, 1987. p.25-36.

SARTI, C. A família como espelho: um estudo sobre a moral dos pobres. Campinas: Autores Associados, 1996.

SINGLY, F. O nascimento do indivíduo individualizado e seus efeitos na vida conjugal e familiar. In: PEIXOTO, C. et al. Família e individualização. Rio de Janeiro: FGV, 2000. p.13-9.

VELHO, G. Individualismo e cultura. Notas para uma Antropologia da sociedade contemporânea. Rio de Janeiro: Zahar, 1981.

VELHO, G. Subjetividade e sociabilidade. Uma experiência de geração. Rio: Zahar, 1986.

VELHO, G. Família e subjetividade. In: ALMEIDA, A. M. et al. (Orgs.) Pensando a família no Brasil. Rio de Janeiro: Espaço e Tempo/UFRRJ, 1987. p.79-87.

MACHADO, L. Z. Familias e individualismo: tendencias contemporáneas en Brasil. Interface _ Comunic, Saúde, Educ, v.4 , n.8, p.11-26, 2001.

Este artículo presenta puntos de reflexión sobre el debate actual respecto al presente y futuro de la "institución familia" y al "valor" de la familia frente a la generalización del individualismo. En la sociedad brasileña, el código relacional hace de la parentela y de la familia un valor que atraviesa toda la sociedad y se articula con el código individualista, constituyendo formas variadas de organización familiar que obedecem a principios de reciprocidad y jerarquía, de acuerdo con las posiciones y situaciones de clase. La generalización inconsistente de las condiciones ciudadanas, puede transformar el principio de la igualdad individual de derechos en la universalización del anonimato, de la indiferencia $y$ de la desensibilización.

PALABRAS CLAVE: Familia; individualismo; reciprocidad. 